Theoretical Mathematics \& Applications, Vol. 12, No. 1, 2022, 1-7

ISSN: 1792-9687(print), 1792-9709(online)

https://doi.org/10.47260/tma/1211

Scientific Press International Limited

\title{
Inequalities Involving Companion Matrix
}

\author{
Mohammad Al-Hawari ${ }^{1}$ and Elham Magableh ${ }^{2}$
}

\begin{abstract}
We give several inequalities involving the Frobenius companion matrix of a polynomial $P$, and solve any equation in involving $c, c^{2}$, and $c^{3}$.

2010 Mathematics Subject Classification: 15A60, 12D10.

Keywords and phrases: Bounds for the zeros of polynomials, Cube companion.
\end{abstract}

1 Mathematics, Faculty of Science and Information Technology, Irbid National University, Jordan.

2 Mathematics, Faculty of Science and Information Technology, Irbid National University, Jordan.

Article Info: Received: December 29, 2021. Revised: January 16, 2022.

Published online: January 28, 2022. 


\section{Introduction}

Let

$$
P(z)=z^{n}+a_{n} z^{n-1}+\cdots+a_{2} z+a_{1}
$$

be a monic polynomial of degree $n \geq 2$ with complex coefficients $a_{1}, a_{2}, \ldots, a_{n}$, where $a_{1} \neq 0$. Then the Frobenius companion matrix of $\mathrm{p}$ is given by:

$$
\mathrm{C}(\mathrm{P})=\left[\begin{array}{ccccc}
-a_{n} & -a_{n-1} & \cdots & -a_{2} & -a_{1} \\
1 & 0 & \cdots & 0 & 0 \\
0 & 1 & \ldots & 0 & 0 \\
\vdots & \vdots & \ddots & \vdots & \vdots \\
0 & 0 & \cdots & 1 & 0
\end{array}\right]
$$

It is Well- Known that the zeros of $\mathrm{p}$ are exactly the eigenvalues of $C(P)$.

Now,

$$
\lambda^{n}+a_{n} \lambda^{n-1}+\cdots+a_{2} \lambda+a_{1}=0
$$

So, by Cayley Hamilton we obtain.

$$
c^{n}+a_{n} c^{n-1}+\cdots+a_{2} c+a_{1} \mathrm{I}=0
$$

Where $C$ is the companion matrix of $P(z)$.

By similar way, we can write replace $\lambda^{2}$ instead of $\lambda$ for

$$
\mathrm{C}^{2}=\left[\begin{array}{cccccc}
\mathrm{b}_{\mathrm{n}} & \mathrm{b}_{\mathrm{n}-1} & \ldots & \mathrm{b}_{3} & \mathrm{~b}_{2} & \mathrm{~b}_{1} \\
-\mathrm{a}_{\mathrm{n}} & -\mathrm{a}_{\mathrm{n}-1} & \cdots & -\mathrm{a}_{3} & -\mathrm{a}_{2} & -\mathrm{a}_{1} \\
1 & 0 & \ldots & 0 & 0 & 0 \\
\vdots & \vdots & \ddots & \vdots & \vdots & \vdots \\
0 & 0 & \cdots & 1 & 0 & 0
\end{array}\right]
$$


and we can write replace $\lambda^{3}$ instead of $\lambda$ for

$$
\mathrm{C}^{3}=\left[\begin{array}{ccccccc}
\mathrm{c}_{\mathrm{n}} & \mathrm{c}_{\mathrm{n}-1} & \cdots & \mathrm{c}_{4} & \mathrm{c}_{3} & \mathrm{c}_{2} & \mathrm{c}_{1} \\
\mathrm{~b}_{\mathrm{n}} & \mathrm{b}_{\mathrm{n}-1} & \cdots & \mathrm{b}_{4} & \mathrm{~b}_{3} & \mathrm{~b}_{2} & \mathrm{~b}_{1} \\
-\mathrm{a}_{\mathrm{n}} & -\mathrm{a}_{\mathrm{n}-1} & \cdots & -\mathrm{a}_{4} & -\mathrm{a}_{3} & -\mathrm{a}_{2} & -\mathrm{a}_{1} \\
1 & 0 & \ldots & 0 & 0 & 0 & 0 \\
0 & 1 & \cdots & 0 & 0 & 0 & 0 \\
\vdots & \vdots & \ddots & \vdots & \vdots & \vdots & \vdots \\
0 & 0 & \cdots & 1 & 0 & 0 & 0
\end{array}\right]
$$

where $b_{j}=a_{n} a_{j}-a_{j-1}$ and $c_{j}=-a_{n} b_{j}+a_{n-1} a_{j}-a_{j-2}$

for $\mathrm{j}=1,2, \ldots \mathrm{n}$, with $\mathrm{a}_{0}=\mathrm{a}_{-1}=0$.

We can solve any equation in solving $C$ such as the following examples.

\section{Example: 1}

Consider the following Clayey Hamilton polynomial

$$
C^{n}+a_{n} C^{n-1}+\ldots .+a_{2} C+a_{1}=0
$$

the companion polynomial is

$$
\mathrm{P}(\mathrm{z})=z^{n}+a_{n} z^{n-1}+\ldots .+a_{2} z+a_{1}
$$

So, the Frobenius companion matrix of $P$ is given by

$$
\mathrm{C}=\left[\begin{array}{ccccc}
-a_{n} & -a_{n-1} & \cdots & -a_{2} & -a_{1} \\
1 & 0 & \ldots & 0 & 0 \\
0 & 1 & \ldots & 0 & 0 \\
\vdots & \vdots & \ddots & \vdots & \vdots \\
0 & 0 & \ldots & 1 & 0
\end{array}\right]
$$


By multiply the original equation by $C^{1-n}$, we have

$$
C+a_{n}+a_{n-1} C^{-1} \ldots .+a_{2} C^{2-n}+a_{1} C^{1-n}=0
$$

By substitution the values for $\mathrm{n}$, we can find the inverse powers for $\mathrm{C}$.

For Example if $n=2$, we get

$$
C+a_{2}+a_{1} C^{-1}=0
$$

And hence,

$$
C^{-1}=\frac{-C-a_{2} I}{a_{1}}
$$

Now, we have the following two cases for the companion polynomial.

Case One: Quadratic formula

Any Equation

$$
\mathrm{C}^{2}+a_{2} \mathrm{C}+a_{1} I=0
$$

has a solution

$$
\mathrm{C}=\left[\begin{array}{cc}
-a_{2} & -a_{1} \\
1 & 0
\end{array}\right]
$$

With eigenvalues

$$
\lambda=\frac{-a_{2} \pm \sqrt{a_{2}^{2}-4 a_{1}}}{2}
$$


Case Two: Cube formula

Any Equation

$$
\mathrm{C}^{3}+a_{3} \mathrm{C}^{2}+a_{2} \mathrm{C}+a_{1} \mathrm{I}=0
$$

has a solution

$$
\mathrm{C}=\left[\begin{array}{ccc}
-a_{3} & -a_{2} & -a_{1} \\
1 & 0 & 0 \\
0 & 1 & 0
\end{array}\right]
$$

With eigenvalues $\lambda$ satisfying the equation

$$
\lambda^{3}+a_{3} \lambda^{2}+a_{2} \lambda+a_{1}=0
$$

\section{Example: 2}

Consider the following Cayley Hamilton polynomial

$$
C^{3}-5 C^{2}+3 C+I=0
$$

Then

$$
\mathrm{C}=\left[\begin{array}{ccc}
5 & -3 & -1 \\
1 & 0 & 0 \\
0 & 1 & 0
\end{array}\right]
$$


Now, we want to solve

$$
\lambda^{3}-5 \lambda^{2}+3 \lambda+1=0
$$

$$
\lambda=1, \lambda=2+\sqrt{5}, \lambda=2-\sqrt{5}
$$

Multiply the equation by $C^{-1}$,

$$
\begin{gathered}
=0 C^{2}-5 C+3 I+C^{-1} \\
C^{-1}=-C^{2}+5 C-3 I \\
C^{-1}=\left[\begin{array}{ccc}
-22 & 16 & 5 \\
-5 & 3 & 1 \\
-1 & 0 & 0
\end{array}\right]+\left[\begin{array}{ccc}
25 & -15 & -5 \\
5 & 0 & 0 \\
0 & 5 & 0
\end{array}\right]-\left[\begin{array}{ccc}
3 & 0 & 0 \\
0 & 3 & 0 \\
0 & 0 & 3
\end{array}\right]=\left[\begin{array}{ccc}
0 & 1 & 0 \\
0 & 0 & 1 \\
-1 & 5 & -3
\end{array}\right]
\end{gathered}
$$

With eigen values $1, \frac{1}{2+\sqrt{5}}, \frac{1}{2-\sqrt{5}}$

Conversely, if we have equation of $C^{-1}$, we can find the eigen values of $C$.

$$
\mathrm{C}^{-1}=\mathrm{C}^{2}+5-3 \mathrm{I}
$$

By multiplying both sides of the equation by $C$, we have

$$
\begin{gathered}
I=C^{3}+5 C^{2}-3 C \\
C^{3}-5 C^{2}+3 C+I=0
\end{gathered}
$$

So,

$$
C=\left[\begin{array}{ccc}
5 & -3 & 1 \\
1 & 0 & 0 \\
0 & 1 & 0
\end{array}\right]
$$




\section{References}

[1] Al-Hawari, M., \& Barahmeh, S. E. M. (2016). Inequalities for Numerical Radius and Spectral Radius. Journal of Advanced Mathematics and Applications, 5(2), 131-133.

[2] Al-Hawari, M., \& Aldahash, A. A. (2013, April). New Inequalities for Numerical Radius of Hilbert Space Operator And New Bounds For The Zeros Of Polynomials. In Journal of Physics: Conference Series (Vol. 423, No. 1, p. 012013). IOP Publishing.

[3] Al-Hawari, M. H. (2016). ZEROS OF POLYNOMIALS BY USING SOME NEQUALITIES. Far East Journal of Mathematical Sciences, 100(10), 1545.

[4] Al-Hawari, M., Hatamleh, R., \& Qazza, A. (2009). Sharper Inequalities for Powers of the Numerical Radii of Hilbert Space Operators. In International Mathematical Forum (Vol. 4, No. 29, pp. 1413-1417).

[5] Al-Hawari, M., \& AL-Askar, F. M. (2013). SOME EXTENSION AND GENERALIZATION OF THE BOUNDS FOR THE ZEROS OF A POLYNOMIAL WITH RESTRICTED COEFFICIENTS. International Journal of Pure and Applied Mathematics, 89(4), 559-564.

[6] Al-Hawari, M. (2013). THE RATIOS BETWEEN THE NUMERICAL RADIUS AND THE SPECTRAL RADIUS OF A MATRIX AND THE SQUARE ROOT OF THE SPECTRAL NORM OF THE SQUARE OF THIS MATRIX. International Journal of Pure and Applied Mathematics, 82(1), 125131.

[7] Al-Hawari, M., \& Abuoshlleh, N. N. (2012). Numerical Radius and Spectral Radius Inequalities for Products and Commutators of Hilbert Space Operators. European Journal of Scientific Research, 87(1), 27-30.

[8] Al-Hawari, M., \& AL-Nawasreh, M. (2017). Study of Partitioned Operators and Its Applications, Theoretical Mathematics and Applications Journal,vol. 7, no. $2,2017,1-15$. 